\title{
Gendered Division of Digital Labor in Parenting: A Qualitative Study in Urban China
}

\author{
Yinni Peng ${ }^{1}$ (D) \\ Accepted: 17 December 2021 / Published online: 14 January 2022 \\ (c) The Author(s), under exclusive licence to Springer Science+Business Media, LLC, part of Springer Nature 2022
}

\begin{abstract}
The gendered division of domestic labor is a key topic in gender and family studies. While there has been extensive discussion of time use and the division of physical, emotional, and mental labor in housework and childcare within couples, the division of digital labor in the family has not been systematically examined. Drawing on qualitative data obtained from 147 parents in 84 urban Chinese families, this study reveals prominent gender differences in digital labor in parenting by comparing urban Chinese mothers' and fathers' use of digital technology and media in searching for parenting information, maintaining online communication with teachers, and shopping online and using online education services for their children. The findings demonstrate an unequal division of digital labor in urban Chinese families, in which mothers shoulder most of the digital labor in parenting. This study enriches the feminist literature by demonstrating the mutual construction of gender and digital technology in the domestic sphere and highlighting a new form of domestic labor divided between husbands and wives in the digital age. This study challenges liberating and progressive myths surrounding digital technology and calls for academic reflection and public attention on its constraining and exploitative implications for women.
\end{abstract}

Keywords Digital labor $\cdot$ Child care $\cdot$ Gender differences $\cdot$ Division of labor $\cdot$ Digital technology $\cdot$ Internet usage $\cdot$ China

The gendered division of domestic labor is a key topic in gender and family studies. Numerous scholars have examined the unequal division of housework and childcare between husbands and wives, revealing how it has negatively affected women's well-being and reproduced patriarchal power in the private sphere (e.g., Bianchi \& Milkie, 2010; Bianchi et al., 2000; Coltrane, 2000; Daminger, 2019; Hochschild, 1979; Hochschild \& Machung, 2003; Medved \& Kirby, 2005; Perry-Jenkins \& Gerstel, 2020). Because of the rapid development and wide penetration of digital technology and media over recent decades, people in many societies have experienced the digitization of family life (Dworkin et al., 2018). For example, empirical studies (Clark, 2013; Dworkin et al., 2018; Lim, 2020; Livingston \& Blum-Ross, 2020) have found that parents in various societies make

Yinni Peng

ynpeng@hkbu.edu.hk

1 Department of Sociology, Room 1044, Academic and Administration Building, Hong Kong Baptist University, Kowloon Tong, Kowloon, Hong Kong, the SAR, China extensive use of digital technology and media in their childcare. Although there has been extensive discussion of time use and the division of physical, emotional, and mental labor in childcare within couples, the division of digital labor within the family has not been systematically examined.

The concept of "digital labor" was originally developed by labor and media scholars to describe "the leisure-oriented, unpaid activities" of Internet users that are appropriated by Internet companies for profit (Gandini, 2020, p. 369). In recent years, the concept of digital labor has been used in multiple disciplines to analyze activities related to production, consumption, leisure, and reproduction that are performed via digital technology and media (Gandini, 2020; Gardner, 2019; Scholz, 2013). Therefore, the concept of digital labor has become a general expression for tasks or activities with a digital component, with the specific implications of the term contingent on the theoretical and empirical context in which it is used (Gandini, 2020; Gardner, 2019; Scholz, 2013). Some scholars (Jarrett, 2016; Scholz, 2013) have argued that unwaged digital labor in the domains of production and consumption is similar to women's labor in 
the family, such as housework and childcare, in its invisible, unpaid, and undervalued nature.

Despite this analogy, there has been little analysis of digital labor in the domestic sphere. Although a few recent studies (Dutta, 2020; Lim, 2020) have noted that mothers are more burdened by the digitalization of work and childcare, they have focused either on mothers' work-family conflicts or on parent-child interactions. Little is known about how digital labor is divided between mothers and fathers in the domestic sphere in general and in the context of childcare in particular. Applying techno-feminists' mutual construction perspective on gender and digital technology, this qualitative study aims to enrich the discussion of digital labor by introducing the concept of "digital labor in parenting" and reveal how digital labor is practiced in the family and shaped by gender. I use the specific concept digital labor in parenting in this study to describe the work and tasks performed by parents through digital technology and media to fulfill their parental duties. Digital labor in parenting mainly comprises the immaterial labor expended in childcare and usually involves intangible work related to information, knowledge, communication, coordination, logistics, and intellectual planning and analysis (Fortunati, 2007; Jarrett, 2016). Digital labor in parenting requires parents to have or attain the necessary digital knowledge, literacy, and skills to satisfy their children's needs. It consumes parents' time, energy, attention, and other mental resources in their daily childcare practices. It is intertwined with the physical, emotional, and mental labor of daily parenting and is characterized by invisibility, fragmentation, and trivialization. Examining the complex intersections of gender, digital technology, and domestic labor can give us a better understanding of the new constraints and forms of inequality that women encounter in the digital age.

\section{The Gendered Division of Domestic Labor and Parenting}

Analyses of the gendered division of domestic labor and its causes and consequences have indicated its heterogeneity across groups and societies and its association with changing macro structures and intricate micro practices and interactions (Bianchi \& Milkie, 2010; Coltrane, 2000; PerryJenkins \& Gerstel, 2020; Shelton \& John, 1996). Childcare is a key component of domestic labor. Although physical and emotional care and moral discipline are central parental duties in most societies, the division of labor and the practice of these tasks by parents are diverse over time and across societies (Arendell, 2000; Glenn et al., 1994; Hochschild \& Machung, 2003; O’Reilly, 2010).

In the twentieth century, the gendered division of labor in childcare was associated with a dominant model of "breadwinning father, homemaking mother" in many societies, especially among middle-class families. In this model, fathers are primarily responsible for economic support while mothers shoulder the load of the physical and emotional care of children. However, this model has been challenged by women's increasing education and employment and by an awareness of gender equality that has paralleled changes in the understanding of motherhood and fatherhood. In the twenty-first century, with more women working and some seeking employment across borders, mothering no longer means simply catering to children's needs in the domestic sphere (Christopher, 2012; Hondagneu-Sotelo \& Avila, 1997). It has been expanded to include breadwinning and coordinating childcare with other caregivers (Christopher, 2012; Ciciolla \& Luthar, 2019; Hondagneu-Sotelo \& Avila, 1997). Meanwhile, the "new dad" discourse has changed the social understanding of fathering from being the economic provider to being the loving nurturer, which calls for men's greater involvement in the physical and emotional care of their children (Atkinson \& Blackwelder, 1993; Dermott, 2008; Kaufman, 2013).

Despite these transformations, gender disparities in childcare persist in both Western and Eastern societies, with mothers still spending more time on childcare and assuming more childcare tasks than fathers (Ciciolla \& Luthar, 2019; Ji et al., 2017; Milkie et al., 2002; Perry-Jenkins \& Gerstel, 2020; Schoppe-Sullivan \& Fagan, 2020). Some scholars have claimed that "mothers do more than fathers across all stages of child development" despite the increased involvement of fathers in childcare (Bianchi \& Milkie, 2010; PerryJenkins \& Gerstel, 2020, p. 426). Although the persistence of an essentialist perception of women as natural caregivers for children and parenthood as a gendered institution can partly explain the stalled revolution for women in relation to childcare (Hochschild \& Machung, 2003), further investigation is needed to reveal how domestic labor in digital form is practiced and divided as family life and childcare are being digitalized.

\section{Technology and the Gendered Division of Domestic Labor}

The application of technology is one of the factors shaping the gendered division of domestic labor (Bittman et al., 2004; Cockburn \& Fürst-Dilić, 1994; Fortunati, 2011; Wajcman, 2006). The twentieth century has witnessed the penetration of domestic technologies, such as the washing machine and microwave oven, into the family. Although these domestic technologies were once believed to save women time and labor for housework and childcare, many scholars have noted that they failed to emancipate women from the drudgery of domestic labor (e.g., Bittman et al., 2004; Habib \& Cornford, 
2002; Livingstone, 1992; Wajcman, 2006). The gendered division of domestic labor is maintained or even reinforced by these "convenient" domestic technologies, either because their use changes the nature of and expectations of quality related to some domestic tasks, thus increasing women's time spent on them, or because the application of domestic technologies is associated with gender roles in the family (Bittman et al., 2004; Habib \& Cornford, 2002; Livingstone, 1992; Wajcman, 2006).

The use of digital technology has recently become an indispensable part of people's family lives in Western and Eastern societies, and has had a prominent effect on childcare. Many scholars have observed that parents widely use digital technology and media in their daily childcare routines, such as seeking out childcare information, maintaining online communication with their children, and managing their children's lives and schooling (e.g., Clark, 2013; Dworkin et al., 2018; Lim, 2020; Livingston \& Blum-Ross, 2020; Wilson $\&$ Yochim, 2017). The application of digital technology and media transcends the boundary between online and offline environments in childcare and makes parents always accessible to their children and engaged ceaselessly in caring duties (Lim, 2020). Meanwhile, with the digitalization of childcare, some physical labor has been replaced by digital labor and the immaterial work related to information, communication, planning, and coordination has become an important part of parenting (Fortunati, 2007). In this context, some studies have noted that mothers are more burdened by the digitalization of childcare, with fathers having only limited involvement in online parenting activities and less interest in the use of online resources and knowledge for parenting (Clark, 2013; Dutta, 2020; Dworkin et al., 2018; He \& Dworkin, 2015; Lim, 2020). Nevertheless, no study has drawn on the experiences of both mothers and fathers to systematically examine how the digital labor associated with childcare is divided between them. Little is known about the ways that digital technology is shaping the gendered division of domestic labor in the new era.

\section{The Mutual Construction of Gender and Technology: A Feminist Perspective}

Feminist scholars have shown increased interest in the interplay between gender and technology (e.g., Cockburn \& Fürst-Dilić, 1994; Fortunati, 2011; Johnson, 2006, 2010; Wajcman, 2006, 2007). Influenced by social constructionism, many feminist scholars examining technology have considered the relationship between gender and technology as a relationship of co-creation and mutual construction (e.g., Faulkner, 2001; Johnson, 2006, 2010; Wajcman, 2007, 2010; Wyatt, 2008). Gender constructs technology because gender ideologies, relations, and institutions shape and are integrated into the development and application of technology in society. Technology simultaneously shapes gender as the innovation and development of "technology reinforces, embodies, or disrupts" preexisting gender relations, patterns, and institutions (Johnson, 2010, p. 36). Therefore, gender and technology are inseparable and evolve together.

The techno-feminist Judy Wajcman (2010) argued that digital technology and gender are interwoven and mutually influencing each other because the sociotechnical process of designing, producing, and using digital technology is gendered, and "women's identities, needs and priorities are configured together with digital" technology (p. 150). She also pointed out that this mutual construction is not a fixed arrangement but rather a dynamic process. It is not only contingent on specific socio-cultural contexts but also reproduced in people's daily activities and interactions. Therefore, Wajcman (2010) called on feminists to investigate the sophisticated interaction between gender and digital technology as "an ongoing process of mutual shaping over time and across multiple sites" (p. 150).

Despite their valuable insights, most relevant feminist discussions have focused on the interplay between gender and digital technology in the public sphere, such as the gendered design and consumption of digital technology and the gendered division of labor in the IT industry (Faulkner, 2001; Wajcman, 2000, 2007, 2010). Less attention has been paid to the mutual construction of gender and digital technology in the domestic sphere. Specifically, we know little about the process of the mutual shaping of gender and digital technology in childcare.

\section{Gendered Parenting in China}

Traditional Chinese parenting is deeply influenced by Confucianism and emphasizes the significance of patriarchal familial relations and raising modest and cooperative members to contribute to a collectivist society (Whyte, 2003). In traditional Chinese families, fathers are authority figures who economically provide for and morally guide children, while mothers are the warm caregivers of children. In postreform China, parenting is influenced by the interaction of economic advancement and marketization, governmental policies, and changed cultural values (Fong, 2004; Jankowiak \& Moore, 2017; Li \& Lamb, 2013). The implementation of the one-child policy for over three decades not only greatly reduced the size of most urban Chinese families, as parents usually had only one child, but also shaped urban parents' perceptions of childcare. With the hopes of the whole family pinned on a single child, most urban Chinese parents adopted a child-centered rearing pattern (Fong, 2004). Chinese parenting in the post-reform period is also influenced by the intensive parenting ideology imported from Western societies 
and the "quality education" (suzhi jiaoyu) discourse advocated by the Chinese government since the 1980s (Jankowiak \& Moore, 2017; Kuan, 2015). Urban Chinese parents, especially middle-class parents, want to raise "happy, healthy, independent, and self-confident" children who are also academically excellent (Jankowiak \& Moore, 2017, p. 92; Kuan, 2015). With increased family incomes, urban Chinese parents tend to invest a great deal of resources on childcare (BinahPollak, 2014; Kuan, 2015). Urban Chinese parents are also expected to acquire a scientific knowledge of childrearing and perform multiple roles, "including teacher, playmate, counselor, and friend," in daily childcare (Jankowiak \& Moore, 2017, p. 92; Kuan, 2015).

Meanwhile, both change and resilience are observed in the gendered division of labor in childcare in post-reform China. Compared with traditional Chinese fathers, fathers in post-reform China participate more actively in the physical and emotional care of children (Jankowiak \& Moore, 2017; Li \& Lamb, 2013). Nevertheless, Chinese mothers are still the primary caregivers and spend more time on caring duties than their husbands do, despite often holding full-time employment and making an economic contribution to their families (Ji et al., 2017). They also play the role of domestic managers in coordinating childcare among family members (Xiao, 2014). Gender inequality in post-reform Chinese families is shaped by the market transition, the weakening of the gender equality discourse once promoted by the socialist state, the asymmetrical gender ideology between men and women, and the "rejuvenation of patriarchal Confucian tradition" (Ji et al., 2017, p. 774).

Missing from the scholarly discussion of gendered parenting in post-reform China is the impact of digitalization on childcare. This oversight is significant given the rapid penetration of digital technology and media in China over the past decade. According to the $46^{\text {th }}$ Statistical Report on Internet Development in China released by the China Internet Network Information Center (CNNIC), there were 940 million Internet users in China in June 2020, for an Internet penetration rate of $67 \%$ (CNNIC, 2020). Male users accounted for $51 \%$ and female users for $49 \%$, and $59 \%$ were aged between 20 and 49 (CNNIC, 2020). In June 2020, there were 766 million users of online search engines, 931 million users of instant messaging, and 749 million users of online shopping, which respectively constituted about $81.5 \%, 99 \%$, and $79.7 \%$ of China's total netizens (CNNIC, 2020). In this context, using digital technology and media has become daily practices of most Chinese parents. For example, urban Chinese parents, especially mothers, rely on media outlets for parenting information as traditional childrearing knowledge and practices are now regarded as outdated (Jankowiak \& Moore, 2017; Peng, 2020). Most kindergartens and schools in China create WeChat or QQ groups to facilitate parent-teacher communication. Teachers use these online communication channels to make announcements, assign homework, and discuss specific issues with parents involving their children. Some kindergartens and schools create their own websites to announce information and have online platforms or applications for children to do their homework. Online shopping is also popular among urban Chinese parents who emphasize the quality and safety of the products they purchase for their children (Hanser \& Li, 2015).

Although a few studies (Chen \& Lunt, 2021; Peng, 2018) have reported on Chinese parents' use of digital technology and media in childcare, they have focused on online parent-child communication in the context of family separation. Little attention has been paid to the impacts of digital technology on spousal interactions in childcare and the gendered division of domestic labor in Chinese families.

\section{Summary of the Current Study}

To fill these gaps in the literature, this study draws on qualitative data from 147 parents in 84 urban Chinese families to compare mothers' and fathers' use of digital technology and media in daily childcare and reveal the ways in which a gendered division of digital labor in parenting is constructed. I focus on three parenting themes involving intensive digital labor: searching for parenting information online, maintaining online communication with teachers, and using online shopping and education services for children. I analyze how gendered perceptions, relations, interactions, and institutions related to childcare produce differences between mothers and fathers in using digital technology and media in these parenting practices. I also reveal how these differences, alongside the characteristics of digital labor, in turn reinforce gendered parenting and consequently construct a new type of gender inequality in the domestic sphere. By decoding the ways in which digital labor in parenting is practiced and divided in urban Chinese families, my study enriches feminist debates on the division of domestic labor and offers an alternative case to reveal the complex interplay between gender, digital technology, and domestic labor in a non-Western socio-cultural context (Coltrane, 2000; Faulkner, 2001). This analysis also contributes to the literature on digital labor by revealing the components, characteristics, and practices of digital labor in the domestic sphere.

\section{Method}

The qualitative data used in this study came from a large project investigating parenting perceptions, daily parenting practices, and spousal and intergenerational relations in childcare in urban Chinese families. Constructivist grounded theory was the main approach guiding data collection and 
data analysis in this study; it emphasizes knowledge production as a co-constitutive process of researchers and participants making sense of the experiences of the participants in their specific socio-cultural context (Charmaz, 2014; Timonen et al., 2018). This approach enabled me to explore how urban Chinese parents understand their parenting practices and construct related meanings while simultaneously reflecting on my role as a researcher and being open-minded to emergent topics or issues, such as digital technology and media (Charmaz, 2014). In-depth qualitative interviewing was the main data collection method given its ability to collect first-hand data on the participants' experiences and daily practices (Charmaz, 2014; Edwards \& Holland, 2013). To supplement the interviews and obtain qualitative data on the participants' interactions and activities and their social contexts, I conducted field observation and collected second-hand data from news reports, online posts, and blogs (Charmaz, 2014; Ravitch \& Carl, 2021). The observational data and second-hand data can be used to corroborate the findings generated from the interview data (Hammersley \& Atkinson, 2019).

\section{Participants}

For the overall project, I defined the participants as parents with dependent children from urban Chinese families. I selected three cities as my field sites: Tai' an in Shandong province, Xiamen in Fujian province, and Shenzhen in Guangdong province. They respectively represent third-tier, second-tier, and first-tier cities in coastal provinces in China. City diversity and accessibility were my main considerations in selecting the field sites. Participants were recruited from different cities at different levels of socio-economic development to avoid creating an overly homogenous or singlesource participant group.

The participants in this study were 147 parents comprising 80 mothers $(54.4 \%)$ and 67 fathers (45.6\%) from 84 urban families. Their ages ranged from 26 to 49 at the time of interview. All participants were married at the time of interview. The parents reported high levels of education, with 75 (51\%) having a Bachelor's degree and 46 (31.3\%) a Master's degree or above. Except for five fulltime mothers, the remaining 142 parents (96.6\%) reported holding full-time jobs in diverse occupations. Their average monthly income was 17,915 yuan. Reflecting the differences between cities in terms of economic development, the average monthly income of parents in the three cities was 28,298 yuan in Shenzhen, 17,069 yuan in Xiamen, and 7,464 yuan in Tai' an. Their income was higher than the average disposable income of urban residents in the three cities, which was about 5,210 yuan per month $(62,522$ yuan per annum) in Shenzhen, 4,918 yuan (59,018 yuan) in Xiamen, and 3,141 yuan (37,695 yuan) in Tai' an in 2019 (Shenzhen
Statistics Bureau, 2020; Tai' an Statistics Bureau, 2020; Xiamen Statistics Bureau, 2020). According to the participants' education levels, incomes, and occupations, the 84 families belonged to the middle class in their respective cities although five of the families were defined as lower-middleclass families.

The participants reported a total of 111 children at the time of interview, with 62 boys (55.9\%) and 49 girls (44.1\%). The children's ages ranged from 4 months to 19 years. The majority of the children (98.2\%) were young and dependent on their parents' care. I use pseudonyms when referring to the participants below to protect their privacy. A demographic summary of the participants is provided in Table 1, and more detailed demographic information of the participants quoted in the article is provided in Table 2.

\section{Recruitment}

I used purposeful sampling in the first stage of participant recruitment (Patton, 1990). I contacted my longterm friends, key informants from previous fieldwork, and research assistants who had local connections in the three selected cities to identify and recruit parents with dependent children from urban families. These contacts were told to recruit both parents from each family if possible. They introduced their relatives, friends, colleagues, classmates, and neighbors who fit the participant profile for interviewing. In the second stage, I used snowball sampling to expand the number of participants by asking some of the interviewed participants to introduce their friends and colleagues for potential recruitment. Although I did not intentionally exclude working-class parents, the networks of contacts recruiting participants were middle class. Due to homophily effects, the friends, colleagues, and neighbors they referred to the study were typically from middle-class families. Therefore, the findings of the study mainly reflect the parenting and digital labor of middle-class families in urban China.

\section{Data Collection}

The data collection was conducted between March 2019 and June 2020. Ethics approval was granted by the Research Ethics Committee of my university before the commencement of data collection. Working with a research assistant, I made five field trips to the three selected cities and conducted 104 face-to-face interviews between March and December 2019. The interviews were held in various places, including the participants' homes and workplaces, our hotel rooms in the field sites, and public spaces, such as cafes and restaurants. Due to the outbreak of COVID-19 in 2020, planned field trips were cancelled, and face-to-face interviews were replaced with online interviews conducted using the Zoom 
Table 1 A Demographic Summary of the Participants

\begin{tabular}{|c|c|c|}
\hline & $n$ & $\%$ \\
\hline \multicolumn{3}{|l|}{ City } \\
\hline Tai'an, Shandong Province & 42 & $28.6 \%$ \\
\hline Xiamen, Fujian Province & 58 & $39.4 \%$ \\
\hline Shenzhen, Guangdong Province & 47 & $32 \%$ \\
\hline \multicolumn{3}{|l|}{ Gender } \\
\hline Male & 67 & $45.6 \%$ \\
\hline Female & 80 & $54.4 \%$ \\
\hline \multicolumn{3}{|l|}{ Pair } \\
\hline Paired participants & $\begin{array}{l}63 \text { (126 } \\
\text { participants) }\end{array}$ & $85.7 \%$ \\
\hline Non-paired participants & 21 & $14.3 \%$ \\
\hline \multicolumn{3}{|l|}{ Age (Year) } \\
\hline $26 \sim 29$ & 11 & $7.5 \%$ \\
\hline $30 \sim 39$ & 107 & $72.8 \%$ \\
\hline $40 \sim 49$ & 29 & $19.7 \%$ \\
\hline \multicolumn{3}{|l|}{ Education } \\
\hline Senior High or Vocational School & 5 & $3.4 \%$ \\
\hline Associate College & 21 & $14.3 \%$ \\
\hline Bachelor Degree & 75 & $51 \%$ \\
\hline Master Degree or Above & 46 & $31.3 \%$ \\
\hline \multicolumn{3}{|l|}{ Occupation } \\
\hline Full-time mother & 5 & $3.4 \%$ \\
\hline Employed or Self-employed & 142 & $96.6 \%$ \\
\hline \multicolumn{3}{|l|}{ Average Monthly Income (Yuan) } \\
\hline$\leq 5,000$ & 25 & $17 \%$ \\
\hline $5,001 \sim 10,000$ & 43 & $29.2 \%$ \\
\hline $10,001 \sim 15,000$ & 17 & $11.6 \%$ \\
\hline $15,001 \sim 20,000$ & 19 & $12.9 \%$ \\
\hline $20,001 \sim 25,000$ & 16 & $10.9 \%$ \\
\hline $25,001 \sim 30,000$ & 7 & $4.8 \%$ \\
\hline $30,001 \sim 35,000$ & 4 & $2.7 \%$ \\
\hline $35,001 \sim 40,000$ & 4 & $2.7 \%$ \\
\hline$>40,000$ & 12 & $8.2 \%$ \\
\hline \multicolumn{3}{|l|}{ No. of Children per Family } \\
\hline 1 & 58 & $69 \%$ \\
\hline 2 & 25 & $29.8 \%$ \\
\hline 3 & 1 & $1.2 \%$ \\
\hline \multicolumn{3}{|l|}{ Gender of Children } \\
\hline Male & 62 & $55.9 \%$ \\
\hline Female & 49 & $44.1 \%$ \\
\hline \multicolumn{3}{|l|}{ Age of Children (Year) } \\
\hline$<6$ & 57 & $51.4 \%$ \\
\hline $6 \sim 12$ & 48 & $43.2 \%$ \\
\hline $13 \sim 15$ & 4 & $3.6 \%$ \\
\hline $16 \sim 19$ & 2 & $1.8 \%$ \\
\hline
\end{tabular}

video conferencing platform. In May and June of 2020, we conducted online interviews via Zoom with 43 parents in Shenzhen. Several steps were taken to protect the participants' confidentiality in carrying out the online interviews. First, online interviews via Zoom and the transferred data were encrypted. For access to each online interview, we sent an individual link and password to the participant via WeChat instant messages. The password ensured that only the participant and the interviewer(s) were able to enter the Zoom meeting. Second, we used the Waiting Room function of Zoom to check the identity of the participant before admittance. Third, we locked the Zoom meeting once the participant had entered to ensure that no third party could enter during the interview.

An informed consent statement was presented or sent to the participants to obtain their consent before commencing the interview. All interviews were conducted in Chinese and lasted for 1 to $2.5 \mathrm{~h}$. Both the offline and online interviews were audio-recorded using an offline digital recorder, with the consent of the participants. The interviews were semistructured focusing on four topics: daily childcare practices, spousal and intergenerational interactions and collaboration in parenting, digital technology and media use in parenting, and reproductive decisions and other parenting issues. Follow-up questions were used to probe for more detailed information. Please see the online supplement for the offline and online interview guide. For the 43 interviews conducted online post-COVID-19, we asked the participants to describe their regular parenting practices and to compare them with their parenting practices during the pandemic to identify childcare differences caused by the outbreak of COVID19. In this article, except for two examples of parents using digital technology and media during the pandemic, I mainly used Shenzhen parents' data on their regular parenting practices to ensure their data were comparable with those collected before the outbreak of COVID- 19 .

The 147 participants included 63 married couples and 21 non-paired parents. For the 63 couples, the husband and the wife were interviewed separately. This arrangement has some advantages for collecting richer and more reliable data. First, the interview data generated by the couple could be cross-checked for corroboration. Second, participants who know that their spouse is also being interviewed are more likely to provide a fair description of the division of labor in childcare and less likely to exaggerate their parenting contributions (Daminger, 2019). Third, when the husband and the wife provided different explanations for the same issue, I was able to analyze the factors shaping this difference. While interviewing the 21 non-paired parents whose spouses were unable or unwilling to participate in the interview, we asked them additional questions about their spouses' duties and practices in daily childcare. When possible, we also asked them to evaluate their spouses' performance in childcare and to describe the spousal differences in childcare. Information on the social context in which the participants and their children lived was obtained through field observation in the 
Table 2 Demographic Information of Quoted Participants

\begin{tabular}{|c|c|c|c|c|c|c|}
\hline Pseudonym & Age & Gender & Education & Occupation & Child's Gender (Age) & City \\
\hline Bei & 40 & Male & Bachelor & Self-employed & Boy (12), Boy (4), Girl (1) & Xiamen \\
\hline Cheng & 35 & Male & Master & IT Staff & Girl (2.5) & Shenzhen \\
\hline Cong & 45 & Female & College & Managerial Staff & Girl (19) & Tai'an \\
\hline Dan & 36 & Male & Bachelor & Real Estate Staff & Girl (7.5) & Tai'an \\
\hline Deng & 41 & Male & Bachelor & Staff & Boy (7) & Xiamen \\
\hline Dong & 41 & Male & Ph.D & Professor & Boy (11) & Shenzhen \\
\hline Fang & 39 & Female & Bachelor & Insurance Agent & Boy (9) & Shenzhen \\
\hline Fei & 39 & Male & Bachelor & Accountant & Girl (12) & Tai'an \\
\hline Gang & 38 & Male & Master & Managerial Staff & Boy (11), Girl (7) & Xiamen \\
\hline Hong & 40 & Female & Bachelor & Stock Investor & Boy (8) & Shenzhen \\
\hline Jiang & 34 & Male & College & IT Staff & Girl (2), Girl (2) & Shenzhen \\
\hline Jie & 40 & Female & Bachelor & Teacher & Girl (7) & Xiamen \\
\hline Jing & 29 & Female & Bachelor & Aviation Weather Forecaster & Boy (1.5) & Xiamen \\
\hline Jun & 34 & Female & Bachelor & Financial Staff & Boy (5) & Shenzhen \\
\hline Kun & 35 & Female & College & Managerial Staff & Boy (7) & Tai'an \\
\hline Lee & 33 & Male & Bachelor & Civil Servant & Boy (3) & Shenzhen \\
\hline Lian & 37 & Female & Bachelor & Nurse & Girl (12) & Tai'an \\
\hline Liang & 40 & Female & Master & Doctor & Girl (2.5), Boy (2.5) & Shenzhen \\
\hline Ling & 28 & Female & Master & Self-employed & Boy (5 months) & Xiamen \\
\hline $\mathrm{Lu}$ & 31 & Female & Master & Legal Personnel & Girl (2) & Tai'an \\
\hline Ma & 35 & Male & Bachelor & Sales Staff & Boy (5) & Tai'an \\
\hline Mei & 32 & Female & Bachelor & Office Staff & Boy (3) & Xiamen \\
\hline Miao & 32 & Female & Master & IT Staff & Girl (2.5) & Shenzhen \\
\hline Ming & 28 & Female & Master & Teacher & Boy (4 months) & Xiamen \\
\hline Ong & 33 & Male & Master & Planning Staff & Boy (3) & Xiamen \\
\hline Ping & 39 & Female & College & Managerial Staff & Boy (13) & Tai'an \\
\hline Qiu & 36 & Male & Bachelor & Teacher & Boy (5.5) & Tai'an \\
\hline Ran & 37 & Male & Bachelor & IT Staff & Girl (7), Boy (2) & Xiamen \\
\hline Shen & 38 & Female & College & Full-time Mother & Girl (10), Boy (8) & Shenzhen \\
\hline Sun & 41 & Male & Bachelor & Employee & Boy (9) & Xiamen \\
\hline Tang & 38 & Male & Master & Senior Manager & Boy (8), Boy (2) & Shenzhen \\
\hline Tian & 38 & Female & Master & Teacher & Boy (8), Boy (0.5) & Tai'an \\
\hline Wang & 29 & Male & Master & Financial Analyst & Boy (4 months) & Xiamen \\
\hline Wen & 37 & Male & Bachelor & Manager & Girl (6) & Xiamen \\
\hline $\mathrm{Wu}$ & 34 & Female & Bachelor & Civil Servant & Boy (4) & Tai'an \\
\hline Xia & 33 & Female & Bachelor & Managerial Staff & Boy (6), Girl (4) & Xiamen \\
\hline Xing & 33 & Female & Bachelor & Staff & Boy (3) & Shenzhen \\
\hline Xue & 37 & Female & Bachelor & Manager & Girl (7.5) & Xiamen \\
\hline Yan & 40 & Female & Master & Administrative Staff & Boy (9) & Xiamen \\
\hline Yao & 30 & Female & Master & Educational Consultant & Girl (5), Boy (1.5) & Shenzhen \\
\hline $\mathrm{Yi}$ & 38 & Female & Master & Engineer & Boy (10) & Shenzhen \\
\hline Ying & 33 & Female & Bachelor & Nurse & Boy (4), Boy (2) & Shenzhen \\
\hline Yue & 35 & Female & Bachelor & Self-employed & Girl (7) & Shenzhen \\
\hline Yun & 35 & Female & Master & Teacher & Girl (11), Girl (6) & Tai'an \\
\hline Zeng & 47 & Male & College & Technical Staff & Girl (19) & Tai'an \\
\hline Zhao & 45 & Male & Bachelor & Civil Servant & Boy (12) & Xiamen \\
\hline Zhou & 38 & Female & Bachelor & Managerial Staff & Boy (6), Boy (2) & Xiamen \\
\hline Zhu & 38 & Female & Bachelor & HR Staff & Boy (11) & Xiamen \\
\hline
\end{tabular}


three cities and online observation via video-conferencing. During the interviews, many participants voluntarily showed digital media and applications on their mobile phones to demonstrate and explain how they used digital technology and media in their daily parenting. We recorded the observational data from fieldwork and interviews in our field notes.

\section{Researcher Positionality}

Before this project, I had rich field experience in Shenzhen and conducted one field trip with my research assistant to Tai' an. My long-term friends in Xiamen also became key informants in this project. I contacted key informants at each field site before the data collection to obtain general information about local social contexts and childrearing practices. Previous fieldwork and personal friendships facilitated our building rapport in the field. Most participants treated us as friends of the key informants who introduced them for interviews. Despite working in Hong Kong, my research assistant and I were women in our late twenties and thirties with mainland Chinese backgrounds, and most participants found it natural and comfortable to talk about their childcare experiences with us. Although we were single women without children, our previous interviews with parents prepared us to have rich discussions about childcare with the participants. Our single, childless status also enabled us to position our participants as experts on childcare, and many participants were willing to educate and prepare us for childcare. Most participants treated the interview as an opportunity to reflect on their parenting practices and share their childcare experiences. Some took the opportunity to vent their anxieties, grievances, and even anger over their spousal and intergenerational childcare collaboration. A few participants misunderstood our role as that of childcare experts and expected us to provide professional advice. On these occasions, we corrected the misunderstanding, gave further explanations about our project, and defined our role as scholars who were interested in childcare research. In the interviews, we showed respect for the participants and listened to their stories with patience and empathy. As a result, most participants provided us with positive feedback after the interview. After the data collection, I maintained regular online communication with some key informants via WeChat to verify my understanding of information on childcare and people's use of digital technology and media. They also forwarded updates on the latest parenting blogs and local policies related to childrearing on Microblog and WeChat.

\section{Data Analysis}

Consistent with grounded theory research, I used coding, memoing, and constant comparisons iteratively across four stages to analyze the data (Bernard \& Ryan, 2010; Charmaz, 2014; Corbin \& Strauss, 2008). In the first stage, I read the full interview transcripts and used open coding to familiarize myself with the data and explore interesting parenting practices, events, or ideas (Bernard \& Ryan, 2010; Charmaz, 2014). After coding a few interview transcripts line by line, I generated an initial list of open codes regarding the participants' parenting practices, interactions, and relations. This initial set of codes was reflected, modified, and expanded upon as it was applied to each interview transcript. I also referred to the parenting literature and ideas that were found to be repeated across several interview transcripts to reflect on the coding process and verify the codes. Some initial codes representing the various uses of digital technology and media in parenting, including online communication, online information, online parenting groups, information sharing, education apps, doing homework online, and shopping online, were developed in this stage.

In the second stage, I focused on analyzing the participants' digital technology and media use in their childcare. Focused coding and memo writing were the main data analysis methods, which helped me cluster open codes into categories and connect my analytical thoughts to the data (Charmaz, 2014; Corbin \& Strauss, 2008). For each transcript, I grouped the open codes related to the use of digital technology and media in parenting into several categories and then developed focused codes for certain activities, such as online shopping for children, online entertainment with children, searching for parenting information online, online communication with teachers, and online services. I also wrote an analytical memo for each case, in which I summarized the main characteristics of each parent's use of digital technology and media in childcare, calculated the time that the parent spent on it, and described the digital tasks carried out by each parent. I also analyzed each parent's explanation for his or her digital practices and associated meanings. I inserted some interview excerpts into the memo to elaborate on the focused codes or support my analytical thoughts. In this stage, I started to generate the connection between focused codes and a preliminary concept of digital labor in parenting.

In the third stage, I primarily used constant comparisons to further identify similarities and nuanced differences within and across cases, although constant comparisons were continuously made throughout the data analysis process (Charmaz, 2014; Corbin \& Strauss, 2008). Within each family, I compared the wife's interview transcript and memo with those of her husband to identify spousal similarities and differences in digital labor in parenting. I then compared interview transcripts and memos across families to identify the main tasks of mothers and fathers in digital labor in parenting and gender differences. I also examined participants' explanations and justifications for these differences. The 
ideas and categories were further grouped into three main themes constituting the key components of digital labor in parenting: online searching for parenting information, online communication with teachers, and online shopping and education services for children (see Table 3).

In the final stage, I focused on verifying the concept and ideas generated in the previous stages by using constant comparisons and triangulation (Charmaz, 2014; Hammersley \& Atkinson, 2019). I made cross-city comparisons to determine whether there were any regional differences in digital labor in parenting. Due to the wide penetration of digital technology and media in China, no prominent regional differences were observed in parental use and related gender differences. I also connected the interview transcript and analytical memo with the observational data in field notes for each case and analyzed the observational data to verify the ideas and findings generated from the interview data (Hammersley \& Atkinson, 2019). For example, the detailed description in my field notes of various study blogs subscribed by a mother in Tai' an corroborated the interview data on her intensive use of study blogs to supervise her son's study. In addition, I regularly read news reports and government policy documents, followed by hotly debated childcare topics online, and consulted with key informants to assess my interpretations of the data and embed my data analysis in the social context (Charmaz, 2014; Hammersley \& Atkinson, 2019).

\section{Results}

Consistent with findings reported in the literature (Clark, 2013; Dutta, 2020; Lim, 2020), most of the mothers in this study reported more time and involvement than the fathers in using digital technology and media for parenting. The 80 mothers reported an average of $4.78 \mathrm{~h}$ per day of overall digital technology and media use (including for work, entertainment, and childcare) and an average of $1.41 \mathrm{~h}$ per day using it for parenting. In comparison, the 67 fathers reported an average of $4.93 \mathrm{~h}$ of overall use per day, of which $0.97 \mathrm{~h}$ were dedicated to parenting. Although on average the fathers spent more time on overall daily use than the mothers, the fathers' average time for parenting was $0.44 \mathrm{~h}$ (about $26 \mathrm{~min}$ per day) less than that of the mothers. Although multiple tasks and activities constituted these parents' digital labor, I identified three main themes that reflected the most intensive digital technology and media use: (1) online searching for parenting information, (2) online communication with teachers, and (3) online shopping and education services for children. The following section details how a gendered division of digital labor in parenting is reflected in these themes and analyzes how the mutual construction of gender and digital technology is demonstrated in the parents' daily childcare practices and interactions.

\section{Online Searching for Parenting Information}

Using digital technology and media to search for parenting information online has become a regular practice among urban Chinese mothers but not fathers. This unequal division of digital labor between mothers and fathers in online searching for parenting information is supported by a gender essentialist perception of women as natural caregivers, gendered parenthood, and prioritizing men's role as breadwinners (Coltrane, 1989; Coltrane \& Adams, 2008; Gaunt, 2006). Meanwhile, women's appreciation of their husbands being busy with paid work, men's devaluation of women's invisible digital labor, and spousal interactions in sharing parenting posts further justified and reinforced the gendered division of digital labor.

\section{Online Searching for Parenting Information by Mothers}

In this study, 76 mothers reported searching online for parenting information and knowledge, and 43 of them reported intensive use of online search. Only four mothers explicitly stated that they never sought online parenting information due to their low level of trust or interest. Many of the mothers subscribed to popular parenting blogs on Microblog and WeChat, regularly followed childcare posts published by the bloggers, and selectively absorbed useful childcare information and parenting knowledge and tips online. Some mothers had also joined online mother communities operating through Web fora or WeChat groups to regularly receive parenting information from peers. When encountering specific problems with their childcare, many mothers actively sought information via Baidu (a Chinese search engine like Google), Zhihu (a Chinese question-and-answer website like Quora), or Little Red Book (a platform for users to share product reviews and personal experiences via short videos and photos).

The focus of their online search was usually in accordance with the growth and development stages of their children. Mothers with young children searched for information and knowledge about the physical care, health, and early development of children. For example, Mei began subscribing to parenting blogs while she was pregnant. At the time of the interview, Mei was mainly reading blogs on Chinese Medicine, which provided her with useful information for the health of her 3-year-old son. As she stated, "They teach you how to deal with a cold and how to nurse children to health. They provide recipes with cases." Mothers with school-aged children paid more attention to blogs or posts about children's study, hobbies or talent classes, parent-child communication, and discipline. For example, to help her 13-year-old son in junior high school, Ping regularly searched for study blogs on her smartphone, subscribed to the study blogs of almost all of the subjects her son was taking, and read the 


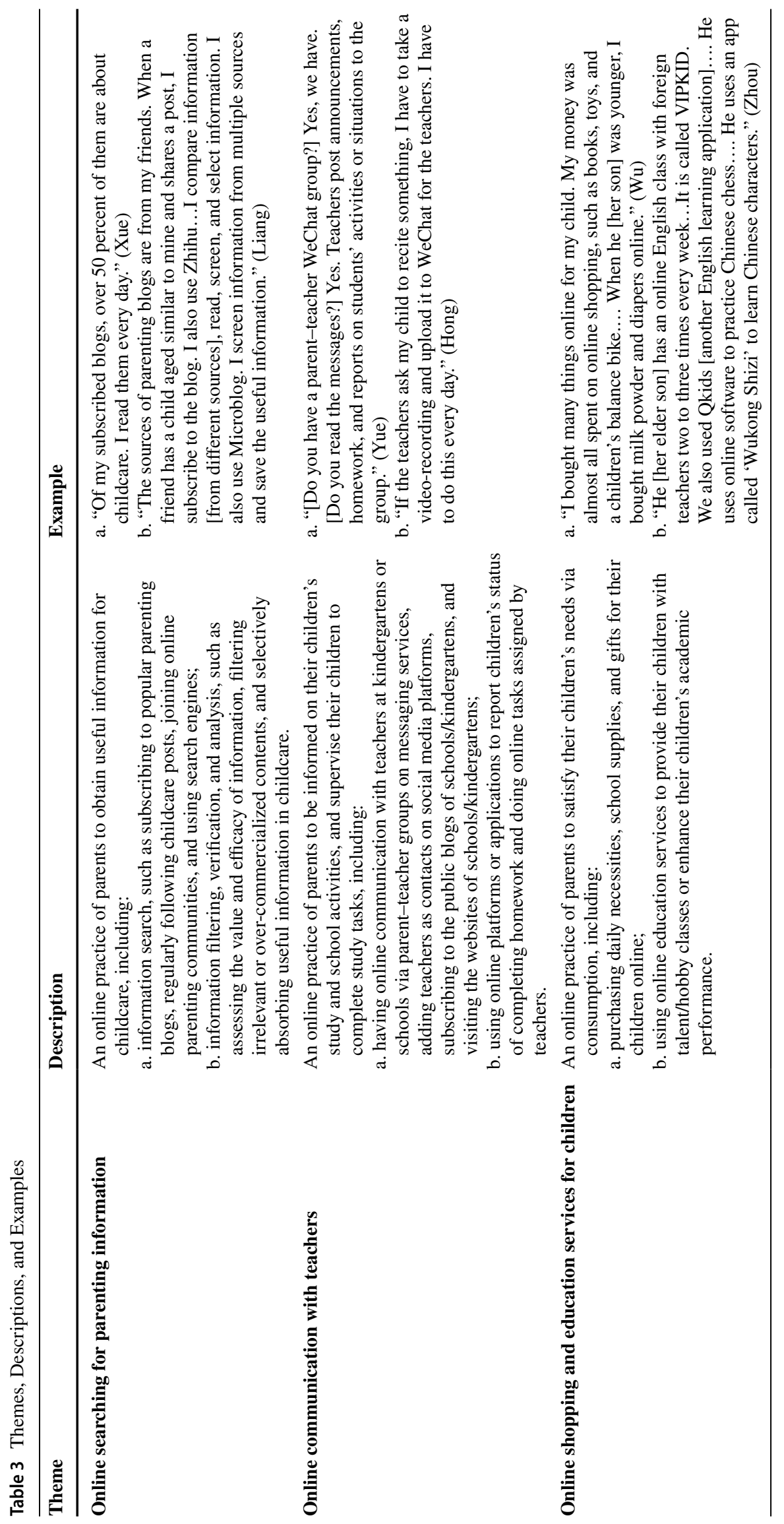


posts whenever she was free. Sometimes, when she found a post useful, she even downloaded and printed it for her son. As she described, "The blogs, Master of Physics and Master of Chemistry... summarize the main knowledge points of the whole textbooks. I find them useful....In case my son asks for help with his homework, I know how to supervise him."

Obtaining online parenting information and knowledge goes beyond the passive receipt of information. In the digital age, people are bombarded by a huge amount of information every day and the mental ability to process, manage, and analyze information has become important (Clark, 2013). Many of the mothers not only applied their digital skills to search for parenting information among various online sources, but also actively analyzed the contents of parenting blogs or fora, evaluated the value of online information and the efficacy of the parenting practices recommended by bloggers or peers, and filtered out irrelevant or useless information. For example, Lu had been reading parenting blogs every day since she gave birth to her now 2-year-old daughter. She believed that filtering and selecting information was necessary because of the commercialization of online blogs. She said, "Some blogs are commercialized, and the products promoted by them are not useful. So, it needs careful screening and analysis." Another mother, Jun, emphasized the uniqueness of each child and argued that mothers should selectively read and apply online parenting information in accordance with their child's particular characteristics.

I subscribed to parenting blogs ... but I would not blindly follow their suggestions. I select some useful information and eliminate inapplicable information.... Every child is unique ... so I selectively read and apply some online parenting information. (Jun, 34, mother of one son, Shenzhen)

Most of the mothers associated their online searches for parenting information with their maternal responsibility. They believed that regularly absorbing useful parenting information and knowledge would enhance their parenting practices and help them make conscientious parenting decisions (Clark, 2013). Even if not all the information was useful to them, they did not mind spending their time on this task. Many of the mothers reported that they benefited and even gained some inspiration from online parenting knowledge. For example, Xia believed that parenting blogs had greatly enriched her knowledge of childrearing and helped her deal with specific childcare problems at various stages.

Look at the WeChat blogs that I subscribe to, most are related to childcare.... I select the blogs in terms of my children's age.... The contents are about how to parent two children, how to help children transition from kindergarten to elementary school, how to help children enhance their mental focus, how to cultivate their interests in hobby classes, and how to manage their time properly.... They have a great impact on my childrearing. (Xia, 33, mother of two children, Xiamen)

\section{Online Searching for Parenting Information by Fathers}

Compared with the mothers, most of the fathers were passive in searching for online parenting information. Only six fathers in this study had regularly searched for and used online parenting information. Most of the fathers reported that they had never or seldom subscribed to parenting blogs, joined parenting fora, or searched for childcare information online. Some fathers occasionally sought information online when they encountered specific problems in childcare. As Ma stated, "I occasionally read some posts. I am interested in those discussing children's education and health.... I hate those parenting posts selling chicken soup for the soul." Just as men are known for "providing token help" for their wives in physical domestic labor, two of the fathers occasionally "helped" their wives with online parenting information screening and analysis after their wives did the initial search (Coltrane, 2000; Treas, 2010, p. 6). For example, Wang believed that his wife was "weak in logic" so he occasionally discussed and analyzed online posts with her.

The mother sometimes, you know, is weak in logic as a young lady. After reading some posts, she does not know how to evaluate them or make a judgment. In this situation, I take a look and discuss it with her. (Wang, 29, father of one son, Xiamen)

\section{"Gendered Interests" and Spousal Interactions}

Most of the parents found it natural for the mothers to spend more time and effort searching for online parenting information than the fathers did, and they attributed this gender difference to "gendered interests." For example, Zhao believed that his wife, as a woman, was more interested in and serious about childcare. He said, "I seldom pay attention to online parenting blogs or posts... She [his wife] likes to subscribe to these blogs and is more serious about this because women are more demanding on childcare." Yan explained her husband's limited interest in parenting blogs by saying, "Fathers seldom read online parenting posts. Fathers, as men, are less interested in this issue compared to women." Their perception of a gendered interest in searching for parenting information is associated with an essentialist understanding of men and women and the gendered institution of Chinese parenthood, in which mothers are regarded as the primary caregivers whose maternal instincts drive them to pay 
greater attention to and have more interest in childcare (Coltrane, 1989; Gaunt, 2006; Jankowiak \& Moore, 2017; Kuan, 2015).

This perceived gendered interest not only serves to justify the gender difference in searching for parenting information online but also reproduces the gendered division of digital labor in daily spousal interactions. Observing their husbands' weak interest in parenting information, many of the mothers realized that they could not rely on their husbands to obtain useful information for childcare. Bearing this in their mind, the mothers cultivated the habits of being constantly alert to online parenting information, filtering for useful information, and sharing it with their husbands. As Jing said, "I know that my husband does not read these blogs. When I find some posts useful, I forward them to him." However, by sharing parenting posts with their husbands, Jing and other mothers relieved their husbands of the task of searching for parenting information online themselves and thereby reinforce the gendered division of digital labor. Many fathers proved this point by arguing that they did not need to search for parenting information because their wives were doing so and would share information with them. As Tang said, "I don't read parenting blogs. My wife reads them. If she reads some good blogs, she forwards them to me." Another father Wang echoed, "I seldom actively search for online information [on parenting].... I know that she [his wife] does it. So, I let her take this task."

Even though most of the mothers had full-time jobs, both mothers and fathers justified fathers' limited engagement with online searching for parenting information as being due to their engagement in paid work. For example, Wang's wife Ming worked as a music teacher in a high school but explained her willingness to shoulder most of the work in searching for parenting information online by mentioning Wang's tough job as a financial analyst at an investment bank. As she said, "He receives parenting information mainly from me. He is too busy with his work. His job is tough." In addition, some fathers attributed their limited use of certain online platforms to the platforms' "feminine" characteristics. As Cheng stated, "Little Red Book is too feminine. I don't use it frequently." Twelve fathers questioned the value of online parenting information. They either criticized many parenting blogs for being over-commercialized or argued that online parenting information was contradictory and useless. As Lee and Sun argued,

I believe that mothers are more likely to be influenced by these [parenting] blogs. These blogs have some commercial elements. Mothers are easily attracted by them. I never pay attention to those blogs. They are nonsense. (Lee, 33, father of one son, Shenzhen)
There are many popular parenting blogs, or blogs about children's education.... I trust only one out of ten. If I cannot verify it, I don't trust it. But my wife is easily bewitched by these- 'listen to this expert, listen to that master.' (Sun, 41, father of one son, Xiamen)

Although their criticism of the commercialization of some parenting blogs and the poor quality of some online parenting information is justified, they did not recognize the time and effort their wives spent on searching for and filtering information. By accusing mothers of being easily "brainwashed" by commercialized blogs or being fooled by online misinformation, these fathers devalued mothers' digital labor in obtaining useful online parenting information and knowledge. As an ongoing and accumulative process, searching for parenting information online requires constant attention to and analysis of a large amount of information, makes continuous demands on time and energy, and demands an investment of effort and mental labor. However, due to the mundane and invisible nature of this digital labor, mothers' efforts and contributions in gathering online parenting information have not been valued or recognized, and fathers' limited contribution to this task is not regarded as problematic within their families.

\section{Online Communication with Teachers}

The digitalization of family life and schooling over the past decade has increased the use of online forms of parent-teacher communication, but also introduced "unprecedented parenting responsibilities" as parents are considered always available and easily accessible (Lim, 2020, p. 65). In this study, online communication with teachers has become an indispensable part of the daily life of parents who have children at kindergartens or schools. They join teacher-parent WeChat or QQ groups, add teachers as "friends" on social media platforms, subscribe to the school's public blog or follow updates on its website, and download the study applications that the school adopts.

The digitalization of children's schooling has increased parents' digital labor in online communication with teachers (Lim, 2020). The intensive digital labor in parent-teacher communication demands the mothers' constant alertness and attention to teachers' messages, their communication and digital skills, and their patience and meticulousness in performing various online tasks. Many of the fathers were passive in relation to this task. The gendered division of digital labor in communicating with teachers is shaped by gendered institutions in the public and private domains, gendered parent-teacher interactions, and spousal interactions and tactics in daily life (Coltrane, 2000; Coltrane \& Adams, 2008; Kemp, 1994). A perception of easier communication 
between mothers and female teachers was used to justify the division of labor for this task. Many of the fathers also used their work demands, poor communication skills, impatience, and criticism of the mothers' performance to leave the unpleasant work to their wives.

\section{Mothers' Online Communication with Teachers}

Fifty-three families in this study reported that the mother was responsible for online communication with teachers and for completing related online work. Only three families reported that the father was the primary parent maintaining online communication with teachers due to their intensive involvement in childcare. Another two families adopted an egalitarian model with husbands and wives equally involved in online parent-teacher communication. After joining teacher-parent WeChat or QQ groups, most of the mothers had to constantly be alert to the messages, announcements, and assignments posted by teachers (Dutta, 2020; Lim, 2020). As Yan said, "You have to check the messages in the parent-teacher WeChat group every day. Teachers post homework information to the group every day." In addition, many mothers had to reply to teachers promptly and construct their messages carefully. Because there are no visible cues in text-based online communication, language becomes the main vehicle to construct one's identity and "online persona" (Wood \& Smith, 2005, p. 60). The mothers felt the need to carefully edit their messages, such as using polite words and a polite tone, to present the image of a good parent online. Lian explained the difference between face-toface and online communication with teachers:

I don't like WeChat ... because it requires an editing process. I have to think about what words I should use. But in my face-to-face communication [with the teachers], I can directly say something and don't need to consider the wording. WeChat communication is different. (Lian, 37, mother of one daughter, Tai' an)

Moreover, the mothers had to observe online communication norms, such as knowing how to ask questions properly and knowing the preferred online communication methods of individual teachers. As Ying explained, "When you ask teachers something, you cannot ask it in a direct way.... If your manner of communication is not good or appropriate, it may affect how teachers treat your child." Another mother Fang described how she varied her online communication in accordance with different teachers' preferences.

[Online communication] highly depends on teachers' styles and preferences.... The previous teacher told parents: 'Don't send me private messages. I don't have time to deal with them. Communicate in our WeChat group. It is open and transparent.' But the current teacher likes private messages.... 'If you have any questions, communicate with me via private messages.' (Fang, 39, mother of one son, Shenzhen)

In their online communication and interactions with teachers, many of the mothers with school-aged children also needed to regularly report children's status of completing homework or extracurricular readings, upload children's homework for teachers to grade, and complete some online tasks assigned by teachers. As Zhu described,

Their teachers require them to recite English words and recite some Chinese texts every day. Sometimes, teachers ask children to read some extracurricular books.... There is an app in WeChat; you can use it to upload the voice recording of children reciting texts or reading books - We [Zhu and her son] do it together. It takes at least one hour ... [and] I am responsible for this. (Zhu, 38, mother of one son, Xiamen)

The digital labor can become overwhelming in certain special periods. Lockdowns imposed to contain the outbreak of COVID-19 in 2020 led to the adoption of homeschooling and online education in many places (Cannito \& Scavarda, 2020; Lian \& Yoon, 2020). These periods of online education at home intensified parents' involvement and digital labor in their children's study (Cannito \& Scavarda, 2020; Lian \& Yoon, 2020). For example, Shen, a 38-year-old mother in Shenzhen, supervised her 10-year-old daughter and 8-year-old son's online classes at home for over a month before they resumed regular schooling in May 2020. As a full-time mother whose husband resumed work in March, Shen was solely responsible for managing her children's online classes. Every day, she had to report her children's health information to their teachers by filling out online forms, and make appropriate arrangements for her two children's online classes. Usually, she arranged for her daughter to take online classes in her bedroom, as her daughter was old enough to be taught how to use the online class system independently. She then assisted her son as he took online classes in the living room, during which she typed on her son's behalf to communicate with the teacher because he was too young to do so. She also took pictures of her children's homework and uploaded them to the parent-teacher QQ groups for the teachers to grade. Shen admitted that she was "exhausted and almost driven crazy" by digital labor during the lockdown period.

\section{Fathers' Online Communication with Teachers}

In contrast to the mothers, most fathers in this study admitted that they paid little attention to online parent-teacher groups. A few fathers did not even join the online groups. Even if they joined these online groups, they seldom communicated with 
teachers. "Lurking" was the word often used by these fathers to describe their status in online parent-teacher groups. As Dong described, "I joined the online parent-teacher group when my child was in the third grade. I never speak in the group. I never pay attention to it. I disable the notification function of the group." In the 53 families in which the mothers shouldered the burden of online parent-teacher communication and related online tasks, fewer than 10 fathers provided occasional help for their wives. For example, Deng downloaded and printed homework from the school's website for his son. Tang filled in the online health report form for his elder son every day during the lockdown period. Two fathers communicated with teachers only in urgent situations or when the mothers were not available. As Dan stated,

[Did you join the parent-teacher WeChat group?] Yes, yes. [Did you contact the teacher?] No. Last year, I communicated with the teacher only once. I did not find my child when I went to school to pick her up. So, I contacted the teacher.... I seldom contact teachers. I only send holiday greetings to teachers during the spring festival. (Dan, 36, father of one daughter, Tai'an)

\section{Gendered Parent-Teacher Communication}

When explaining the gendered division of labor in online parent-teacher communication, many of the parents resorted to the perceived easiness of communication between female parents and female teachers. Because of gender segregation in the labor market, kindergarten and school teaching is regarded as a female-dominated occupation (Coltrane \& Adams, 2008; Kemp, 1994). Meanwhile, gendered parenthood defines mothers as the primary caregivers who are good at care, communication, and managing social relations (Coltrane, 2000; Coltrane \& Adams, 2008). Thus, gendered institutions in both the public and private spheres make it seem natural and appropriate for mothers to have greater involvement in online communication with teachers. As Tian, a 38-year-old mother, said, "I am the one communicating with the teacher. The teacher is a woman. So, it is easy to communicate between a female teacher and the mother." Being busy with work was also frequently mentioned by many of the fathers to explain their limited online communication with teachers. For example, working as a senior manager at an IT company, Tang explained, "The mother does most of the communication with teachers. She always reads the messages sent by teachers in the WeChat group. Because I am quite busy, I don't do that." Some fathers used their poor communication skills as an excuse for their limited online communication with teachers. As Qiu said, "I am not good at it [communication]. I don't know why. Maybe, it is because my communication ability is deteriorating."
The gendering of online communication is also constructed and even reinforced in daily parent-teacher interactions and spousal interactions. Many of the parents stated that teachers usually contacted the mother even if both the mother and the father had joined the online parent-teacher group. Teachers' preferences in online parent-teacher communication thus indirectly reinforced the perception of mothers as the primary parents in online communication and smoothed communication between mothers and teachers. When the fathers observed that their wives shouldered this task and shared teachers' messages with them, they found it unnecessary to communicate directly with teachers. As Gang stated,

Teachers usually contact the mother, not me. I am silent in the WeChat group and only read messages. It is better to let one parent communicate with the teachers. Otherwise, the teachers would get confused.... The mother shares information with me. (Gang, 38, father of two children, Xiamen)

Despite their limited online communication with teachers, some fathers were demanding of their wives' performance on this task. Kun, a 35-year-old mother with a 7-year-old son, was criticized by her husband because she did not reply to a teacher's message immediately. Kun worked in a private company and her self-employed husband managed a small advertising agency. Although her husband had more flexibility with his work and had joined the parent-teacher WeChat group, he still believed that Kun should be responsible for online communication with teachers. As Kun complained,

My husband criticized me, 'How busy are you? Why don't you reply to the teacher's message immediately?'

... There are lots of messages in the parent-teacher group. So, I mute the group notifications. But the problem is that I may not be able to reply to the teacher's messages immediately when I mute the group. The teacher pushed me to reply to the message by mentioning me in the group message. (Kun, 35, mother of one son, Tai'an)

Kun's husband used his criticism of her to define online communication with teachers as his wife's duty and push her to be more attentive to teachers' messages. In contrast, the fathers were active in online communication with teachers in a few families, and the mothers expressed appreciation for their sharing or shouldering of this task. As Yao, a 30-yearold mother, stated, "He [her husband] voluntarily shoulders this [online communication with teachers]. This initiative is highly commendable. He shoulders all the work quietly.... He does this to support my career." The criticism by Kun's husband and Yao's appreciation both reflect a normative expectation and reinforce the gendered division of digital labor in online parent-teacher communication. 


\section{Gendered Division of Online Study Tasks}

In most families, the gendering of online parent-teacher communication led to a gendered division of completing online study tasks. Because the mothers were responsible for communicating with teachers and had more information about their children's study and school life, related online tasks or assignments naturally became their work. Some mothers had to take on these tasks because of their husband's reluctance to do so. For example, when she was busy, Jie would occasionally ask her husband to help their 7-year-old daughter with her homework, such as by taking a video of the child reading an English text and uploading it to the WeChat group for the teacher to grade. However, her daughter did not want the father to supervise her homework because he was impatient with the task. To support her daughter's study, Jie had to compromise and shoulder the digital labor in online communication with teachers and completing the related online study tasks. Jie's case was indirectly corroborated by some fathers who complained and even felt annoyed by the trivial and troublesome online tasks assigned by teachers. As Fei complained, "Frankly speaking, I feel annoyed by the parent-teacher group. Posting homework, making announcements.... Many tasks are online, doing this task online, doing that task online, online safety education, and so on." These fathers' complaints about and impatience in completing online tasks reveals how much time, energy, and effort mothers were investing in online parent-teacher communication and interactions.

In addition, some study application settings limit the number of registered users from each family, thus constraining mothers from sharing digital labor with other family members and indirectly shaping the gendered division of digital labor between mothers and fathers. Tian's supervision of her 8-year-old elder son's homework is a typical example. The math teacher of her elder son sometimes used the Homework Box application to assign online homework. Tian therefore needed to download and register the application, and login whenever there was assigned homework. Although Tian found it convenient to use the application to check her elder son's homework, its settings allowed only one parent to register, which prevented her from getting help from her husband for this task. As Tian said,

The Homework Box app allows only one parent of each child to register. I registered it. My husband always has overtime work [so] he cannot guarantee the time for supervising my son's homework. After I registered it, it can be done only via my mobile phone. (Tian, 38, mother of two sons, Tai' an)

\section{Online Shopping and Education Services for Children}

With the proliferation of e-commerce and rise of the platform economy, online shopping and the use of online education services have become popular in China in the past decade. Urban Chinese parents benefit from online shopping and education services as they offer them more convenience and autonomy and save time and physical labor (Ayadi \& Muratone, 2020; Burningham et al., 2014). However, online shopping and education services inevitably burden parents with more digital labor, of which the lion's share is shouldered by mothers in most families. As shopping is regarded as women's work, many of the parents attributed the gendered division of this type of digital labor to mothers' feminine interest and better skills in online shopping (Casey \& Martens, 2007; DeVault, 1991). Maternal love for their children and the fathers' engagement in paid work were also used to explain the gender difference. For online education services, the gendered division of digital labor was explained by the greater involvement of the mothers in related online tasks and the fathers having little interest. The few fathers who actively participated in online shopping and education services highlighted their paternal love for their children or associated it with certain masculine characteristics, such as richer knowledge and better technical and calculation skills.

\section{Online Shopping for Children and the Gendered Division of Digital Labor}

Online shopping has become a part of the new "digital mundane" for Chinese parents and constitutes another component of digital labor in parenting (Wilson \& Yochim, 2017, p. 27). All the families in this study reported regularly shopping online. Parents of young children used online shopping to purchase milk powder, diapers, clothes, and toys, while parents with school-aged children bought food, clothes, shoes, books, and stationery online. Shopping is a skillful daily activity, in which shoppers must "constantly sort through the information available" for thousands of products, decide which of the products they need, consider their economic resources, balance family needs, and finally make the purchase (DeVault, 1991, p. 68). Compared with visiting physical stores, online shopping is convenient and timesaving, and offers more consumption information and options for parents (Ayadi \& Muratone, 2020; Burningham et al., 2014). Despite its advantages, online shopping inevitably adds to parents' digital labor, through such tasks as searching for information, comparing websites and prices, reviewing online comments, and placing online orders (Ayadi \& Muratone, 2020; Burningham et al., 2014). The related digital labor is often 
invisible, as parents make purchases on their computers or smart phones at home or during breaks at work.

Many parents in this study were very careful in selecting products for their children online. As Ling, a 28-yearold mother, stated, "I mainly rely on flagship stores. If I don't find the products in flagship stores, I compare brand reputations, online scores, and review posts." The digital labor involved in online shopping becomes more intensive on certain holidays or during online shopping seasons, when various online promotions and sales are used by e-commerce merchants to attract consumers. In addition to regular practices, online shopping during holidays and shopping seasons requires parents to apply skills of calculation and coordination in strategically using various coupons and discounts to purchase goods. Xing described how complicated the task was when she attempted to use online coupons and promotions to purchase toys and clothes for her son during Double 11 , an unofficial shopping season in China:

I bought him [her son] clothes and toys. [Double 11] is so complicated. There are various coupons and promotions.... Although the system calculates all the discounts for you when you place orders, you still need to strategically use these coupons and promotions.... It is quite annoying. (Xing, 33, mother of one son, Shenzhen)

Of the 62 families in this study that explicitly reported a division of labor in online shopping for children, 54 families adopted a mother-dominant model. Mothers in these families spent more time on online shopping and regularly purchased daily necessities online for their children. The fathers occasionally bought toys, books, snacks, and shoes as gifts to demonstrate their paternal love for their children. Six families reported that the fathers actively participated in online shopping for children and demonstrated an egalitarian model in this task. In two families, the fathers bought children books, toys, snacks, and materials for craft classes online. In another three families, the fathers were responsible for purchasing milk powder and toys for their children online, while the mothers bought the clothes and shoes. Only two out of the 62 families reported that the fathers did most of the online shopping for their children. In one family, the wife Lian admitted that she did not like shopping, while her husband Fei favored their daughter and regularly shopped online for her. In the other family, the wife Miao identified her daughter's needs and told her husband what they needed to buy. Her husband Cheng then conducted the online research to compare the quality and prices of products and purchased those with the highest cost-performance ratio. As Cheng explained,
We usually have discussions when we buy something for our child. Most of the time, my wife tells me, 'Do some research on diapers. We need to buy some diapers.' ... Selecting which brand? That's my job.... Sometimes, when my wife has selected some products ... I look for online discounts or coupons. I am better at this. She does not care. (Cheng, 35, father of one daughter, Shenzhen)

When explaining the gender difference in online shopping for children, many of the parents reasoned that mothers are "shoppers par excellence" who are more careful in selecting products for children and have better shopping knowledge and skills than fathers (Casey \& Martens, 2007, p. 2). They not only perceived shopping as a feminine skill but also associated online shopping with maternal love and care for their children and thus as a way of mothering (Burningham et al., 2014; Casey \& Marterns, 2007; DeVault, 1991). As Yi, a 38-yearold mother, explained, "All online shopping is done by me. ... The father in our family is not very careful.... I care more about childcare." Jiang, a 34-year-old father, echoed this point by saying, "I am not good at [online shopping]. The mother does this work." Some fathers also resorted to the "gendered interest" of mothers in online shopping. They perceived online shopping as a leisure practice and argued that mothers shouldered this work because they enjoyed it. As Tang stated,

She [His wife] likes online shopping. She knows those [online shopping] apps. She has downloaded all of the apps and makes comparisons to see which offers better products and which has cheaper prices. She downloads the apps from time to time.... I don't even know the names of these apps. (Tang, 38, father of two sons, Shenzhen)

Other fathers used their work demands to explain their limited involvement in online shopping for children. As Bei stated, "My wife buys clothes and daily necessities [for the children online]. I seldom do it. I don't have time." Of the few fathers who regularly shopped online for their children, some associated it with their paternal love for their children. These cases, to some extent, deconstructed the feminine nature of shopping. Other fathers highlighted using their better skills and richer knowledge to tone down the feminine characteristics of online shopping. For example, two fathers in the egalitarian model used online shopping to purchase milk powder from overseas for their children. They argued that they took on this task because they had more knowledge of overseas shopping or better English skills for selecting reliable agents or online shops. Another father Cheng emphasized his better skills in searching for and calculating online coupons and discounts to justify his intensive involvement in online shopping. 


\section{Online Education Services for Children and the Gendered Division of Digital Labor}

Under the quality education discourse and fierce competition in schooling in post-reform China, regular education at schools is considered insufficient for these middle-class parents to raise well-rounded children (Kuan, 2015). Most parents send their children to extracurricular and hobby classes to enrich their children's cultural capital and improve their academic performance (Kuan, 2015). Online education services have developed rapidly in China in recent years. By June 2020, 381 million people in China had used online education services, which constituted about $40.5 \%$ of all Chinese netizens (CNNIC, 2020). Fifty-two families in this study reported using online education services for their children. Many of the parents, especially the mothers, believed that online education services provided extra educational resources for their children and offered more convenience and autonomy for parents. As Xue explained,

We are a double-income family. Using an education app is convenient. I prefer to select online classes for my daughter's extracurricular courses. When we have online classes, what I need to do is connecting to the Internet one minute before the class starts. I don't need to drive her to the classroom or consider where to park my car.... Another advantage is that I can select the time [of the online class] and the teacher... I have autonomy. (Xue, 37, mother of one daughter, Xiamen)

Parents with young children used online education services or applications to equip their children with basic Chinese, English, or math before they entered the formal education system. Parents with school-aged children used online education services to enhance their children's academic performance or provide talent or hobby classes. For example, Yun actively used multiple online education applications for her 6-year-old daughter's early education and transition to primary school:

I used some cards, apps, and software to teach my [younger] daughter basic literacy. The software is like an online game, passing each challenge. My daughter is interested in it. I search for these apps every day and think about how to inspire my daughter's interest in literacy.... I use some story-reading apps, such as Anniekids and Fan Deng Little Readers, for my daughter... We have an online English class on VIPKID [an English online learning app]. (Yun, 35, mother of two daughters, Tai'an)

Another mother Cong even found an online essay writing course for her 19-year-old daughter who was in the final year of senior high school and preparing for her college entrance examination. Like online shopping, online education services increase parents' digital labor despite reducing their physical labor. The digital labor in using online education services involves exploring different online classes or applications, selecting an appropriate one for their children, downloading the application and registering with the service, and paying the tuition fees online. Sometimes, parents also need to communicate with the service providers and select suitable class timeslots or courses.

All but one of the 52 families using online education services reported that the mothers were responsible for most of the work. In addition to selecting and installing the related software, the mothers also supervised their children in using the applications and, especially in the case of younger children, often accompanied them in the online classes. They sometimes helped their children communicate with the teachers in online classes. The involvement of fathers was limited in most of the families. Many fathers knew that their children were using online education services but could provide little detail. Wen was the only father who actively sought online education services for his daughter. Another two fathers offered occasional help. Ong took on the technical task of downloading and installing the application. As he said, "I usually take on the technical part. After that, my wife is responsible for the education part." Ran provided some supervision of his daughter's online English reading classes at weekends after his wife had selected and downloaded the application, registered with the service, and paid the tuition fee online.

Using online education services is not an isolated task, and it is typically inextricable from other online practices, such as searching for information and communicating online. Given that the mothers performed most of the online communication with teachers and regularly received parenting information from various sources, using online education services naturally became their work, especially when many parents treated online education services as part of their children's education.

Many fathers believed that they did not need to pay much attention to online education because their wives were taking good care of it. For example, Lee stated that using an application to help teach English to his 3-year-old son was a good idea, but when he noticed pop-up ads in his WeChat, he found it unnecessary to read them as his wife had already taken care of it. He admitted that he was not attentive when his wife discussed selecting English-language learning applications for their son. As he confessed, "I did not pay much attention to it. As long as she selects it, I am fine with it." The couple arranged for their son to have online English classes three times a week. The mother attended the online classes with their son while Lee laid beside them and played with his phone. Lee attributed his limited involvement to his lack of interest in a naïve application for children. As he said, "I know my behavior is not good. But, as an adult, I 
really don't have any interest in it [the application]." Some fathers defined themselves as traditional men to justify their limited involvement in this digital labor. For example, Zeng, the husband of Cong, defined himself as an old-fashioned man who was not good at using new technologies. As he explained, "I seldom use it [online searching and online education]. Her mother uses a lot. You know, I am an oldfashioned man and have limited access to new things."

\section{Discussion}

The findings from the current study demonstrate an unequal division of labor in most urban Chinese families, in which mothers shoulder most of the digital labor in parenting. The discussion of a gendered division of digital labor in parenting enriches the feminist literature by demonstrating how a new form of domestic labor, and its division between mothers and fathers, is constructed with the penetration of digital technology into the family. It also contributes to technofeminist debates by revealing the ways and the process through which gender and digital technology are mutually constructed in the domestic sphere.

As feminist scholars point out, both gender and its relationship with technology are mainly expressed and constructed in people's "doing" (Gardner, 2019; Wajcman, 2007, 2010; West \& Zimmerman, 1987). In this study, the gendered division of digital labor and the mutual construction of gendered parenting and digital technology are produced in the daily childcare practices and interactions of Chinese parents. Gender is integrated into the process of applying digital technology and media in parenting as gender essentialist perceptions of men and women, gender roles and institutions related to childcare, and gendered interactions collectively affect how parents use digital technology and media for childcare (Coltrane, 1989; Coltrane \& Adams, 2008; Gaunt, 2006; Wajcman, 2010).

First, an essentialist perception of femininity and masculinity affects parents' understandings of who should perform what digital tasks in childcare (Coltrane, 1989; Gaunt, 2006). Many of the parents expressed a belief that mothers, as women, are instinctively more interested in childcare and shopping, are more careful and patient in mundane and trifling work, and have better communication and relationship management skills. In other words, the essentialist perception of feminine characteristics defines mothers as more appropriate for and capable of shouldering digital labor in parenting (Coltrane, 1989; Gaunt, 2006). In contrast, fathers are regarded as having little interest in "feminine" tasks, being careless and impatient when managing trivial matters, and having poor communication skills. These stereotyped masculine characteristics make excuses for fathers' limited involvement in digital labor in parenting. When both mothers and fathers internalize these essentialist perceptions and attribute gender differences in digital labor to "natural differences" between women and men, the unequal division of digital labor in parenting is justified and regarded as unproblematic (Gaunt, 2006).

Second, gendered institutions and roles related to childcare in both the public and private spheres shape the division of digital labor in parenting (Coltrane, 2000; Coltrane \& Adams, 2008; Kemp, 1994). Observing the gender bias in the teaching occupation, many of the parents attributed mothers' greater involvement in online parent-school interactions to their easier communication with female teachers. This accommodates gender norms defining childcare as women's duties and assuming that female parents and female teachers have more common interest in childcare. As offline shopping for family is regarded as women's work, mothers shouldering most of the work of online shopping for children is regarded as a natural extension of the offline division of this labor (Casey \& Martens, 2007; DeVault, 1991). With gendered parenthood defining mothers as the primary caregivers, most of the mothers attributed their doing the majority of the digital labor in parenting to their maternal love and responsibility (Coltrane, 2000; Coltrane \& Adams, 2008). Meanwhile, because of men's gendered roles as breadwinners in the family and economic producers in the public sphere, many of the parents explained the fathers' limited involvement in the digital labor in parenting by highlighting the demands of their paid work (Coltrane \& Adams, 2008; Kemp, 1994; Treas, 2010).

Third, parents' daily practices, spousal interactions, and gendered parent-teacher interactions reinforce the gendered division of digital labor in parenting. Although most of the couples seldom explicitly negotiated who should perform what digital tasks, their unspoken interactions shaped the division of labor. For example, when the fathers lurked in online parent-teacher groups, their silence sent a message to the mothers that they would not participate in online communication with teachers. When the fathers seldom paid attention to online parenting information, this neglect also indicated to the mothers that they should not count on their husbands for this task. Silence and neglect are tactics that implicitly define the gendered division of digital labor between husbands and wives and avoid opening it up for negotiation. Occasionally, the fathers were explicit, through criticism and impatience, in reinforcing the gendered division of digital labor in parenting. As mentioned above, one father criticized his wife for replying late to a teacher's WeChat message, and another father showed impatience in helping his child with online homework. In contrast, many of the mothers were proactive in shouldering multiple digital tasks in childcare. They also shared parenting information and teachers' messages with their husbands via digital 
media. One mother explicitly expressed her appreciation for her husband's intensive involvements in online communication with teachers. The mothers' proactivity in digital labor, their willingness to share information with fathers, and their appreciation for fathers' contributions sustained and reproduced the gendered division of digital labor. In addition, teachers as a third-party initiated contact with the mothers instead of the fathers. Their actions also sent an external message to the parents and indirectly legitimized the gendered division of digital labor in the family.

At the same time, the penetration of digital technology and media in family life and the nature and characteristics of digital labor transform how childcare practices and tasks are performed by parents and reproduce gendered parenting. As digital technology and media reduces the physical strength needed to perform certain parenting tasks (e.g., online shopping and online education services), the fathers assumed that the mothers could take on these tasks more easily, and the mothers found it unnecessary to seek help from the fathers. Meanwhile, the multi-functional nature of digital technology and media blurs the boundary between childcare and personal leisure. Given that mothers perform many childcare duties on their mobile phones by browsing webpages, clicking, scrolling, and typing messages, it is hard for other family members to tell the difference or draw boundaries between their childcare and personal leisure. Moreover, digital labor is scattered and usually penetrates into daily work and activities (Dutta, 2020; Lim, 2020). For instance, some of the mothers browsed online parenting posts or online shops while taking a short break from work. Other mothers engaged in online communication with teachers while doing housework at night. Thus, the reduced physical strength of digital labor, the blurred boundary between digital labor and personal entertainment, and the easy penetration of fragmented digital labor into other daily activities obscure or even render invisible mothers' efforts in performing digital labor.

The nature and characteristics of digital labor also affect how parents assess its value and the fairness of the division of digital labor (Fortunati, 2011; Scholz, 2013). As digital labor is considered easy to perform and intertwined with leisure, many of the fathers equated the mothers' digital labor in parenting with hobbies or personal interest and assumed they enjoyed these activities. Depicting mothers' digital labor in parenting as a form of leisure ignores how digital labor in parenting demands constant attention and mental labor, interrupts daily work and life, and places mothers under constant pressure to engage in childcare (Dutta, 2020; Lim, 2020). It thus not only conceals the immaterial labor and digital skills performed by mothers in childcare but also devalues their contribution to this new type of domestic labor. The invisible and undervalued nature of digital labor makes fathers' limited involvement unproblematic and leaves mothers' requests for their more extensive participation unheard. Thus, applying digital technology and media in childcare has reinforced the gendered construction of parenting by pushing women to undertake additional invisible and undervalued labor. Furthermore, through their continuous different uses of digital technology and media in daily childcare, parents gradually create a new form of gendered labor division in the domestic sphere: the gendered division of digital labor in parenting.

Although the critical reflection on the mutual construction of gendered parenting and digital technology presented in this study aims to call more attention to the exploitation of women by applying digital technology and media in the domestic sphere, it does not rule out the potential for resisting and transforming the gendered division of digital labor. A few of the fathers did report having an equal share of and even performing more digital labor in parenting. Their cases decouple the essentialist link between women and digital labor in parenting, and indirectly prove that mothers doing more digital labor in parenting is a gendered construction (West \& Zimmerman, 1987). These cases also indicate another direction for the mutual construction of gendered parenting and digital technology: increasing men's share of digital labor in parenting is a way of undoing gender in the domestic sphere and challenging patriarchy in the digital age (Deutsch, 2007).

\section{Limitations and Future Research Directions}

There are some limitations of this study that ought to be acknowledged. First, the data and related findings are mainly from middle-class families in urban China. It is unclear how working-class parents in urban China and rural Chinese families share digital labor in parenting. Second, due to the limited scope and length of the article, some differences in digital labor in parenting between fathers and mothers are not examined, such as online entertainment with children, and using applications to record children's growth and development. Third, although the estimated average time that the parents spent using digital technology and media provides a general picture of the gender differences between mothers and fathers in digital labor, possible recall bias may exist. Therefore, more accurate measurements or data collection methods will be needed for future research. Fourth, as the digitalization of domestic labor and the negotiation and division of digital labor in the family are ongoing processes, a longitudinal research design will help researchers better understand the dynamic interplay between the family and the digital world. For future research, it would be valuable to conduct comparative studies, use a longitudinal research design, and employ new data collection methods to examine 
the nuanced differences across classes and societies in the gendered division of digital labor in parenting and reveal transitions in the division of digital labor over time.

\section{Practice Implications}

Many people regard digital technology and media as promising, convenient, and beneficial in the digital era. However, the current findings subvert the positive stereotype of digital technology and media by revealing their negative implications for the gendered division of labor in parenting. The digitalization of parenting creates more digital labor for mothers who are already shouldering most of the physical, emotional, and mental labor of childcare. Moreover, due to its invisible and scattered nature, the digital labor performed by women in childcare is not recognized, let alone valued. Men's limited involvement in digital labor in parenting is rarely questioned. As feminists have argued, the personal is political (Rogan \& Budgeon, 2018). By revealing the constraining and exploitative side of the digitalization of parenting, this study questions the optimistic association between gender equality and digital technological advancement, and calls for more academic and public attention to the implications of the digitalization of daily life on gender relations and practices. My findings can assist government organizations, nongovernment actors, and practitioners in understanding some of the new pressures and problems faced by women in the digital age, such as how the digitalization of childcare affects women's physical and mental health, marriage quality and satisfaction, and family tensions. My study is also valuable in calling for reflection on the impacts of technological developments in general and on the penetration of digital technology and media into family life in particular.

\section{Conclusion}

By comparing the use of digital technology and media of mothers and fathers in the context of parenting in urban Chinese families, I revealed a new type of gender inequality in the domestic sphere: an unequal division of digital labor in parenting. Applying the techno-feminist perspective of mutual construction of gender and digital technology (Faulkner, 2001; Wajcman, 2000, 2007, 2010), I decoded how gendered parenting and digital technology co-produce and shape each other in the domestic sphere. My findings enrich feminist debates on the association between the gendered division of labor and digitalization in the family. By challenging liberating and progressive myths surrounding digital technology and media, my study highlights its constraining and exploitative implications for women in the private sphere and calls for academic reflection, public attention, and policy interventions on a new form of gender inequality in the digital age.
Supplementary Information The online version contains supplementary material available at https://doi.org/10.1007/s11199-021-01267-w.

Acknowledgements The author thanks the participants and key informants for their support. The data collection would not be completed without the assistance of Ma Huan. The author also thanks the anonymous reviewers of Sex Roles for their constructive comments.

Author Contribution The author solely conducted research design and data analysis, drafted and revised the manuscript, and approved the final manuscript.

Funding The research is funded by the General Research Fund from the University Grants Committee of Hong Kong [HKBU 12605218].

Data and Code Availability To protect the participants' confidentiality, their personal information and detailed data will not be shared. The list of open codes and focused codes in the article is available upon request.

\section{Compliance with Ethical Standards}

Ethics Approval Human research ethical approval was obtained from the Research Ethics Committee of Hong Kong Baptist University [HASC/17-18/0431].

Consent to Participate An informed consent statement was presented or sent to the participants before commencing the interviews. The informed consent was obtained from all participants in both face-toface and online interviews.

Conflicts of Interest The author declares no potential conflicts of interest with respect to the research, authorship, and/or publication of this article.

\section{References}

Arendell, T. (2000). Conceiving and investigating motherhood: The decade's scholarship. Journal of Marriage and the Family, 62(4), 1192-1207. https://doi.org/10.1111/j.1741-3737.2000.01192.x

Atkinson, M. P., \& Blackwelder, S. P. (1993). Fathering in the 20th century. Journal of Marriage and the Family, 55(4), 975-986. https://www.jstor.org/stable/352777

Ayadi, K., \& Muratore, I. (2020). Digimums' online grocery shopping: The end of children's influence? International Journal of Retail \& Distribution Management, 48(4), 348-362. https://doi.org/10. 1108/IJRDM-09-2019-0291

Bernard, H. R., \& Ryan, G. W. (2010). Analyzing qualitative data: Systematic approaches. SAGE Publishing.

Bianchi, S. M., \& Milkie, M. A. (2010). Work and family research in the first decade of the $21^{\text {st }}$ century. Journal of Marriage and Family, 72(3), 705-725. https://doi.org/10.1111/j.1741-3737. 2010.00726.x

Bianchi, S. M., Milkie, M. A., Sayer, L. C., \& Robinson, J. P. (2000). Is anyone doing the housework? Trends in the gender division of household labor. Social Forces, 79(1), 191-228. https://www. jstor.org/stable/2675569

Binah-Pollak, A. (2014). Discourses and practices of child-rearing in China: The bio-power of parenting in Beijing. China Information, 28(1), 27-45. https://doi.org/10.1177/0920203X13517617 
Bittman, M., Rice, J. M., \& Wajcman, J. (2004). Appliances and their impact: The ownership of domestic technology and time spent on household work. The British Journal of Sociology, 55(3), 401423. https://doi.org/10.1111/j.1468-4446.2004.00026.x

Burningham, K., Venn, S., Christie, I., Jackson, T., \& Gatersleben, B. (2014). New motherhood: A moment of change in everyday shopping practices? Young Consumers, 15(3), 211-226. https:// doi.org/10.1108/YC-11-2013-00411

Cannito, M., \& Scavarda, A. (2020). Childcare and remote work during the COVID-19 pandemic: Ideal worker model, parenthood and gender inequalities in Italy. Italian Sociological Review, 10(3S), 801-820. https://doi.org/10.13136/isr.v10i3S.399

Casey, E., \& Martens, L. (2007). Introduction. In E. Casey \& L. Martens (Eds.), Gender and consumption: Domestic cultures and the commercialization of everyday life (pp. 1-11). Ashgate.

Charmaz, K. (2014). Constructing grounded theory (2nd ed.). SAGE Publishing.

Chen, S., \& Lunt, P. (2021). Chinese social media: Face, sociality, and civility. Emerald Publishing Limited.

China Internet Network Information Center (CNNIC). (2020). Statistical report on internet development in China (September 2020). Retrieved on December 10, 2020 from https://cnnic.com.cn/IDR/ ReportDownloads/202012/P020201201530023411644.pdf

Christopher, K. (2012). Extensive mothering: Employed mothers' constructions of the good mother. Gender \& Society, 26(1), 73-96. https://doi.org/10.1177/0891243211427700

Ciciolla, L., \& Luthar, S. S. (2019). Invisible household labor and ramifications for adjustment: Mothers as captains of households. Sex Roles, 81(7), 467-486. https://doi.org/10.1007/s11199-018-1011-x

Clark, L. S. (2013). The parent app: Understanding families in the digital age. Oxford University Press.

Cockburn, C., \& Fürst-Dilić, R. (1994). Introduction: Looking for the gender/technology relation. In C. Cockburn \& R. Fürst-Dilić (Eds.), Bring technology home: Gender and technology in a changing Europe (pp. 1-21). Open University Press.

Coltrane, S. (1989). Household labor and the routine production of gender. Social Problems, 36(5), 473-490. https://www.jstor.org/ stable/3096813

Coltrane, S. (2000). Research on household labor: Modeling and measuring the social embeddedness of routine family work. Journal of Marriage and the Family, 62(4), 1208-1233. https://www.jstor.org/ stable/1566732

Coltrane, S., \& Adams, M. (2008). Gender and families (2nd ed.). Rowman \& Littlefield Publishers.

Corbin, J., \& Strauss, A. (2008). Basics of qualitative research: Techniques and procedures for developing grounded theory (3rd ed.). SAGE Publishing.

Daminger, A. (2019). The cognitive dimension of household labor. American Sociological Review, 84(4), 609-633. https://doi.org/ 10.1177/0003122419859007

Dermott, E. (2008). Intimate fatherhood: A sociological analysis. Routledge.

Deutsch, F. M. (2007). Undoing gender. Gender \& Society, 21(1), 106-127. https://doi.org/10.1177/0891243206293577

DeVault, M. (1991). Feeding the family: The social organization of caring as gendered work. University of Chicago Press.

Dutta, D. (2020). Mobile phones as interactive technologies mediating gendered work-life conflict: A qualitative study on women in STEM. Sex Roles, 82(11-12), 659-672. https://doi.org/10.1007/ s11199-019-01088-y

Dworkin, J., Rudi, J. H., \& Hessel, H. (2018). The state of family research and social media. Journal of Family Theory \& Review, 10(4), 796-813. https://doi.org/10.1111/jftr.12295

Edwards, R., \& Holland, J. (2013). What is qualitative interviewing? Bloomsbury Publishing.
Faulkner, W. (2001). The technology question in feminism: A view from feminist technology studies. Women's Studies International Forum, 24(1), 79-95. https://doi.org/10.1016/S0277-5395(00) 00166-7

Fong, V. L. (2004). Only hope: Coming of age under China's one-child policy. Stanford University Press.

Fortunati, L. (2007). Immaterial labor and its machinization. Ephemera, 7(1), 139-157. https://www.ephemerajournal.org/sites/default/ files/7-1fortunati.pdf

Fortunati, L. (2011). ICTs and immaterial labor from a feminist perspective. Journal of Communication Inquiry, 35(4), 426-432. https://doi.org/10.1177/0196859911417713

Gandini, A. (2020). Digital labour: An empty signifier? Media, Culture \& Society, 43(2), 369-380. https://doi.org/10.1177/0163443720948018

Gardner, N. (2019). New divisions of digital labour in architecture. Feminist Review, 123(1), 106-125. https://doi.org/10.1177/0141778919879766

Gaunt, R. (2006). Biological essentialism, gender ideologies, and role attitudes: What determines parents' involvement in childcare. Sex Roles, 55(7), 523-533. https://doi.org/10.1007/s11199-006-9105-0

Glenn, E. N., Chang, G., \& Forcey, L. R. (1994). Mothering: Ideology, experience, and agency. Routledge.

Habib, L., \& Cornford, T. (2002). Computers in the home: Domestication and gender. Information Technology \& People, 15(2), 159-174. https://doi.org/10.1108/09593840210430589

Hammersley, M., \& Atkinson, P. (2019). Ethnography: Principles in practice (4th ed.). Routledge.

Hanser, A., \& Li, J. C. (2015). Opting out? Gated consumption, infant formula and China's affluent urban consumers. The China Journal, 74(1), 110-128. https://doi.org/10.1086/681662

He, Y., \& Dworkin, J. (2015). Cyber dads: What are fathers doing online? Fathering, 13(3), 219-230. https://doi.org/10.3149/fth.1303.219

Hochschild, A. (1979). Emotion work, feeling rules, and social structure. American Journal of Sociology, 85(3), 551-575. https://www. jstor.org/stable/2778583

Hochschild, A., \& Machung, A. (2003). The second shift: Working parents and the revolution at home. Viking Penguin.

Hondagneu-Sotelo, P., \& Avila, E. (1997). I'm here, but I'm there: The meanings of Latina transnational motherhood. Gender \& Society, 11(5), 548-571. https://www.jstor.org/stable/190339

Jankowiak, W. R., \& Moore, R. L. (2017). Family life in China. Polity Press.

Jarrett, K. (2016). Feminism, labour and digital media: The digital housewife. Routledge.

Ji, Y., Wu, X., Sun, S., \& He, G. (2017). Unequal care, unequal work: Toward a more comprehensive understanding of gender inequality in post-reform urban China. Sex Roles, 77(11), 765-778. https:// doi.org/10.1007/s11199-017-0751-1

Johnson, D. G. (2006). Introduction. In M. F. Fox, D. G. Johnson, \& S. V. Rosser (Eds.), Women, gender, and technology (pp. 1-11). University of Illinois Press.

Johnson, D. G. (2010). Sorting out the question of feminist technology. In L. L. Layne, S. L. Vostral, \& K. Boyer (Eds.), Feminist technology (pp. 36-54). University of Illinois Press.

Kaufman, G. (2013). Superdads: How fathers balance work and family in the 21st century. New York University Press.

Kemp, A. A. (1994). Women's work: Degraded and devalued. Prentice Hall.

Kuan, T. (2015). Love's uncertainty: The politics and ethics of child rearing in contemporary China. University of California Press.

Li, X., \& Lamb, M. (2013). Fathers in Chinese culture: From stern disciplinarians to involved parents. In D. Shawalb., B. Shwalb, \& M. Lamb (Eds.), Fathers in cultural context (pp. 15-41). Routledge.

Lian, B., \& Yoon, S. (2020). Burdens, resilience, and mutual support: A comparative study of families in China and South Korea amid the COVID-19 pandemic. Journal of Comparative Family Studies, 51(3), 337-346. https://doi.org/10.3138/jcfs.51.3-4.009 
Lim, S. S. (2020). Transcendent parenting: Raising children in the digital age. Oxford University Press.

Livingstone, S. (1992). The meaning of domestic technologies: A personal construct analysis of familial gender relations. In R. Silverstone \& E. Hirsch (Eds.), Consuming technologies: Media and information in domestic spaces (pp. 113-130). Routledge.

Livingston, S., \& Blum-Ross, A. (2020). Parenting for a digital future: How hopes and fears about technology shape children's lives. Oxford University Press.

Medved, C. E., \& Kirby, E. A. (2005). Family CEOs: A feminist analysis of corporate mothering discourses. Management Communication Quarterly, 18(4), 435-478. https://doi.org/10.1177/0893318904273690

Milkie, M. A., Bianchi, S. M., Mattingly, M. J., \& Robinson, J. P. (2002). Gendered division of childrearing: Ideals, realities, and the relationship to parental well-being. Sex Roles, 47(1), 21-38. https://doi.org/10.1023/A:1020627602889

O'Reilly, A. (ed). (2010). 21st century motherhood: Experience, identity, policy, agency. Columbia University Press.

Patton, M. (1990). Qualitative evaluation and research methods (2nd ed.). SAGE Publishing.

Peng, Y. (2018). Migrant mothering in transition: A qualitative study of the maternal narratives and practices of two generations of ruralurban migrant mothers in Southern China. Sex Roles, 79(1-2), 16-35. https://doi.org/10.1007/s11199-017-0855-7

Peng, Y. (2020). Bringing children to the cities: Gendered migrant parenting and the family dynamics of rural-urban migrants in China. Journal of Ethnic and Migration Studies, 46(7), 1460-1477. https://doi.org/10.1080/1369183X.2018.1510308

Perry-Jenkins, M., \& Gerstel, N. (2020). Work and family in the second decade of the 21st century. Journal of Marriage and Family, 82(1), 420-453. https://doi.org/10.1111/jomf.12636

Ravitch, S. M., \& Carl, N. M. (2021). Qualitative research: Bridging the conceptual, theoretical, and methodological (2nd ed.). SAGE Publications.

Rogan, F., \& Budgeon, S. (2018). The personal is political: Assessing feminist fundamentals in the digital age. Social Sciences, 7(8), 1-19. https://doi.org/10.3390/socsci7080132

Scholz, T. (2013). Introduction: Why does digital labor matter now? In T. Scholz (Ed.), Digital labor: The Internet as playground and factory (pp. 1-9). Routledge.

Schoppe-Sullivan, S., \& Fagan, J. (2020). The evolution of fathering research in the 21st century: Persistent challenges, new directions. Journal of Marriage and Family, 82(1), 175-197. https://doi.org/ 10.1111/jomf.12645

Shelton, B. A., \& John, D. (1996). The division of household labor. Annual Review of Sociology, 22(1), 299-322. https://www.jstor. org/stable/2083433

Shenzhen Statistics Bureau. (2020). The statistical report of economic and social development of Shenzhen in 2019. Shenzhen Government
Online. (In Chinese). Retrieved on August 14, 2020 from https:// www.sz.gov.cn/zfgb/2020/gb1149/content/post_7350867.html

Tai' an Statistics Bureau. (2020). The statistical report of economic and social development of Tai'an in 2019. Tai'an Statistical Information Network. (In Chinese). Retrieved on August 14, 2020 from https://tjj.taian.gov.cn/art/2020/4/1/art_46885_8982390.html

Timonen, V., Foley, G., \& Conlon, C. (2018). Challenges when using grounded theory: A pragmatic introduction to doing GT research. International Journal of Qualitative Methods, 17(1), 1-10. https:// doi.org/10.1177/1609406918758086

Treas, J. (2010). Why study housework? In J. Treas \& S. Drobnic (Eds.), Dividing the domestic: Men, women, and household work in crossnational perspective (pp. 3-18). Stanford University Press.

Wajcman, J. (2000). Reflections on gender and technology studies: In what state is the art? Social Studies of Science, 30(3), 447-464. https://www.jstor.org/stable/285810

Wajcman, J. (2006). The feminization of work in the information age. In L. L. Layne, S. L. Vostral, \& K. Boyer (Eds.), Feminist technology (pp. 80-97). University of Illinois Press.

Wajcman, J. (2007). From women and technology to gendered technoscience. Information, Community and Society, 10(3), 287-298. https://doi.org/10.1080/13691180701409770

Wajcman, J. (2010). Feminist theories of technology. Cambridge Journal of Economics, 34(1), 143-152. https://doi.org/10.1093/cje/ben057

West, C., \& Zimmerman, D. H. (1987). Doing gender. Gender \& Society, 1(2), 125-151. https://doi.org/10.1177/0891243287001002002

Whyte, M. (2003). Introduction: China's revolutions and intergenerational relations. In M. Whyte (Ed.), China's revolutions and intergenerational relations (pp. 3-30). University of Michigan Press.

Wilson, J. A., \& Yochim, E. C. (2017). Mothering through precarity: Women's work and digital media. Duke University Press.

Wood, A. F., \& Smith, M. J. (2005). Online communication: Linking technology, identity \& culture (2nd ed.). Routledge.

Wyatt, S. (2008). Feminism, technology and the information society: Learning from the past, imagining the future. Information, Communication \& Society, 11(1), 111-130. https://doi.org/10.1080/ 13691180701859065

Xiamen Statistics Bureau. (2020). The statistical report of economic and social development of Xiamen in 2019. China Statistical Information. (In Chinese). Retrieved on August 14, 2020 from https://www.tjen.org/tjgb/13fj/36232_5.html

Xiao, S. (2014). "Yan Mu Ci Zu": The intergenerational collaboration and conflicts in childrearing among urban families in contemporary China. Sociological Studies, 6, 148-171. (In Chinese). https:// doi.org/10.19934/j.cnki.shxyj.2014.06.007

Publisher's Note Springer Nature remains neutral with regard to jurisdictional claims in published maps and institutional affiliations. 